\title{
Rozkład naprężeń w krzyżowym złączu spawanym z uwzględnieniem rzeczywistego kształtu spoiny
}

\section{Stress distribution in cross welded joint taking into account the real shape of weld}

\section{Streszczenie}

Złącza spawane ze względu na niejednorodność właściwości mechanicznych, strukturalnych oraz kształtu spoiny są w konstrukcji miejscem powodującym spiętrzanie naprężeń. Najczęściej w obliczeniach przyjmuje się, że kształt spoiny jest jednakowy na całej długości, a zarys nie odbiega od teoretycznego. W artykule przedstawiono rozkład naprężeń w spoinie wykonanej na próbkach stalowych (S355J2+N), której kształt przeniesiono do analizy metodą elementów skończonych przez skanowanie 3D. Uzyskane wyniki porównano $z$ wynikami dla spoiny o promieniu zaokrąglenia linii wtopienia równym $1 \mathrm{~mm}$.

Słowa kluczowe: naprężenia, spawanie, złącze

\section{Abstract}

Welded joints due to their nonhomogeneous mechanical, structural and geometrical properties are the reason for stress concentration in the construction. Generally in the calculation it is assumed that the shape of the weld is uniform over the entire length, and the outline does not deviate from the theoretical one. This article shows the distribution of stress in the weld performed on specimens made of S355J2+N steel, the shape of which was transferred to the finite element analysis by application of 3D scanning. The results were compared with those obtained from the model of the weld with welding toe equal to $1 \mathrm{~mm}$.

Key words: stress, welding, welded joint

\section{Wstęp}

Spawanie jest najbardziej rozpowszechniona metodą łączenia elementów konstrukcji stalowych. Coraz częściej stosuje się także automatyzację tego procesu. $\mathrm{O}$ ile, nie jest to skomplikowane w przypadku długich, prostych spoin, to dla niewielkich elementów, przy często utrudnionym dostępie, jest problematyczne i kosztowne, a czasem wręcz niemożliwe. Spawanie ręczne pozostanie zatem jeszcze istotnym etapem procesów technologicznych w wytwórniach konstrukcji stalowych. Trzeba jednak pamiętać, że kształt spoiny układanej przez spawacza charakteryzuje się zmiennymi wartościami kąta lica oraz promienia zaokrąglenia linii wtopienia, ponadto występuja na niej miejscowe podtopienia i nieciągłości.

W tym opracowaniu przedstawiono analizę zbliżonego do rzeczywistości rozkładu naprężeń w złączu i porównaniu jej do rozkładu naprężeń w próbce zamodelowanej według teoretycznych założeń. Analizie i modelowaniu poddano złącze typu $\mathrm{K} \mathrm{z}$ dodatkową obustronną pachwiną. Materiałem do badań była stal S355J2+N. Analogiczne złącze przebadano eksperymentalnie pod względem trwałości zmęczeniowej w [1]. Dzięki skanowaniu 3D próbek otrzymano model powierzchniowy, a następnie po dodatkowej obróbce komputerowej poddano go analizie metodą elementów skończonych (MES).

\section{Próbki do badań}

\section{Wykonanie próbek}

Do badań wykorzystano dwie próbki o kształcie i wymiarach przedstawionych na rysunku 1 . Do ich wyko-

Mgr inż. Przemysław Stasiuk - Firma Formopex, Strzelce Opolskie, dr hab. inż. Aleksander Karolczuk, prof. PO Politechnika Opolska, mgr inż. Wiesław Kuczko - Politechnika Poznańska. Autor korespondencyjny/Corresponding author: przemyslaw.stasiuk@formopex.pl 


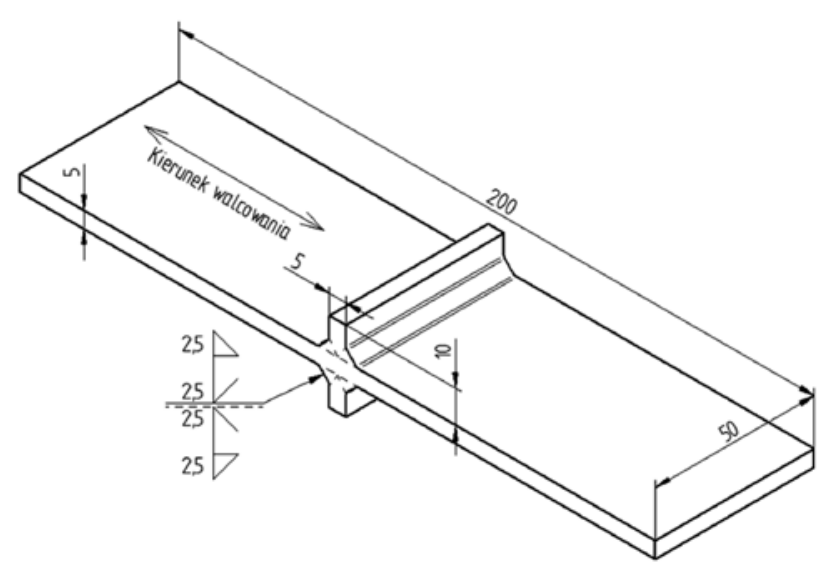

Rys. 1. Kształt i wymiary próbki

Fig. 1. Shape and dimensions of a sample

nania posłużyła płyta o grubości $5 \mathrm{~mm}$, z której wycięto plazmowo wzdłuż kierunku walcowania pas o szerokości $60 \mathrm{~mm}$. Pas ten został następnie pocięty na pile taśmowej na pojedyncze elementy długości $200 \mathrm{~mm}$ i $10 \mathrm{~mm}$. Spawanie wykonano metodą MAG w osłonie mieszaniny $\operatorname{Ar}(92 \%)$ i $\mathrm{CO}_{2}(8 \%)$. Po spawaniu próbkę poddano frezowaniu (obustronnie) na wymiar $50 \mathrm{~mm}$.

\section{Skanowanie 3D}

Do skanowania próbek wykorzystano skaner ATOS I firmy GOM wykorzystujący białe światło strukturalne. Dla obu stron każdej próbki wykonano po 5 skanowań, uzyskując współrzędne punktów, które następnie zostały zamienione na siatkę trójkątów i zapisane jako stereolitografia ( ${ }^{*}$.stl). Umożliwiło to odwzorowanie próbki z dokładnością 0,02 mm (odległość między punktami). Na rysunku 2 przedstawiono model rzeczywisty $\mathrm{i}$ jego odwzorowanie wirtualne.
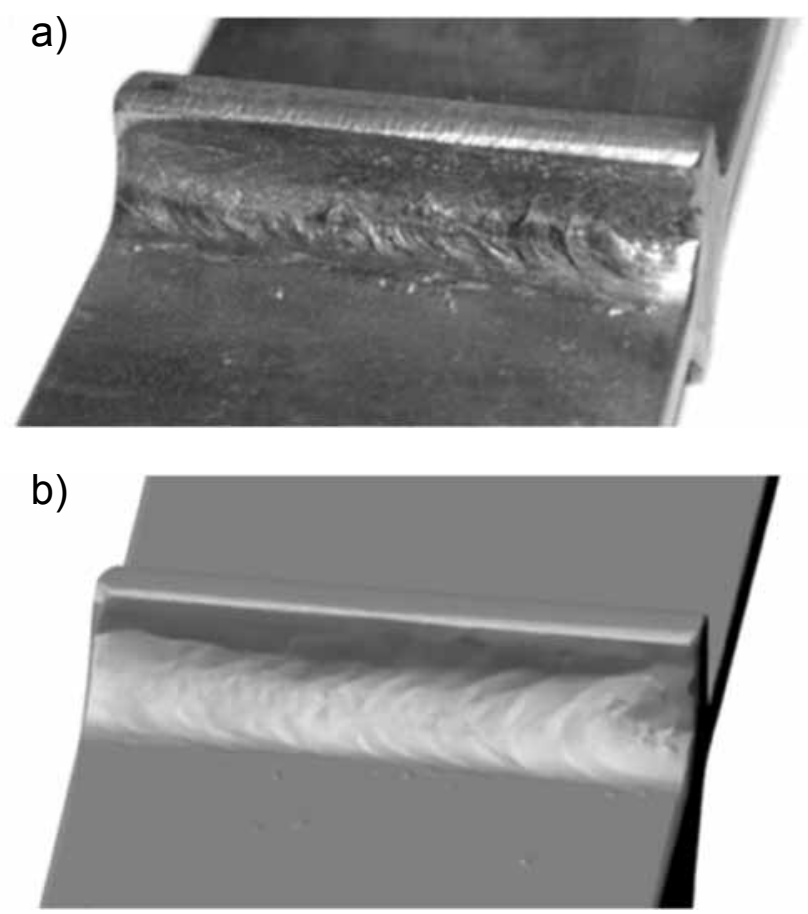

Rys. 2. Próbka do badań: a) element rzeczywisty, b) model wirtualny Fig. 2. Sample for tests: a) the real element, b) the virtual model

\section{Model do obliczeń MES}

W celu zaimportowania modelu do programu MES konieczna była jego dalsza obróbka komputerowa. Aby przyspieszyć obliczenia, ograniczono model, pomijając fragmenty próbki niewpływające na rozkład naprężeń w spoinie. Następnie podzielono model w osiach teoretycznej symetrii na cztery części i wprowadzono dodatkowy podział płaszczyzn modelu (korzystniejsze zagęszczenie siatki MES w miejscach spodziewanej koncentracji naprężeń). Konwersja modelu *.stl do bryłowego oraz operacje obróbki komputerowej spowodowały zniekształcenie modelu. Obniżenie dokładności odwzorowania wynosiło od 0,01 do 0,05 mm, czyli ostatecznie dokładność (odległość między punktami) modelu wirtualnego wahała się od 0,03 do $0,07 \mathrm{~mm}$.

\section{Model porównawczy}

W celu weryfikacji otrzymanych wyników z modelem teoretycznym utworzono obiekt porównawczy w formie próbki o geometrii (rys. 3) zgodnej z wytycznych Międzynarodowego Instytutu Spawalnictwa (IIW) [2] dla metody efektywnego naprężenia w karbie. Różnica polega na tym, że wytyczne zakładają wykonanie spoiny pachwinowej, a co za tym idzie - brak pełnego przetopu w próbce.

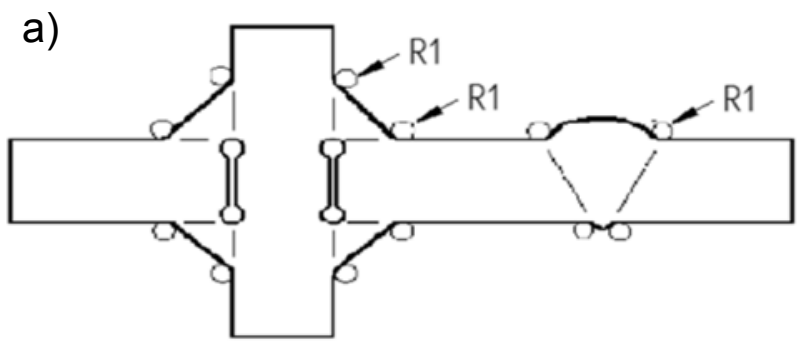

b)

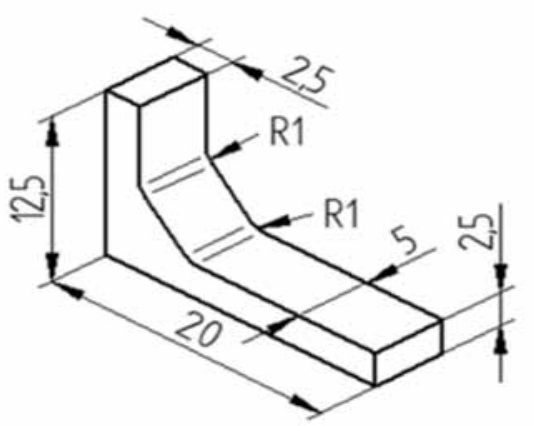

Rys. 3. Próbka porównawcza: a) przyjęta geometria, b) geometria próbki wg IIW

Fig. 3. The comparative sample: a) the applied geometry, b) the geometry of a sample acc. to IIW

\section{Analiza MES}

Po włączeniu modeli do programu MES (Femap v10.3) przystąpiono do nakładania siatki elementów skończonych. Istotną rolę odgrywa tu dobór odpowiedniego rozmiaru elementów. W pracach $[3,4]$ przyjęto $0,025 \div 0,03 \mathrm{~mm}$ w miejscach maksymalnego zagęszczenia siatki, z uwzględnieniem promienia 
zaokrąglenia linii wtopienia i grubości blachy próbki. Przypadki te dotyczą modeli o jednolitej geometrii, a nie rzeczywistych próbek. W pracy [5] przedstawiono analizę modelu ze skanera 3D. Model dyskretny został zbudowany z ośmiowęzłowych heksahadronów o wymiarach $0,025 \times 0,078 \mathrm{~mm}$.

Uwzględniając dokładność odwzorowania omawianego przypadku, przyjęto, że wstępnie wymiar elementu skończonego będzie wynosił od 0,05 mm w obszarze linii wtopienia, przez $0,1 \mathrm{~mm}$ w pozostałej części spoiny, do $1 \mathrm{~mm}$ na końcach próbki. Aby zweryfikować to założenie, przeprowadzono wstępną analizę dla wycinka badanego elementu, przy czym wybrano fragment o najbardziej zróżnicowanej geometrii. Wyniki analizy wstępnej przedstawiono w tablicy I oraz na rysunku 4.

Do utworzenia modelu dyskretnego posłużono się dziesięciowęzłowymi tetrahadronami (4 węzły główne oraz dodatkowo po jednym na każdej krawędzi). Na podstawie analizy wstępnej podjęto decyzję o zastosowaniu wymiarów siatki jak dla przypadku nr 3 (rys. 5).

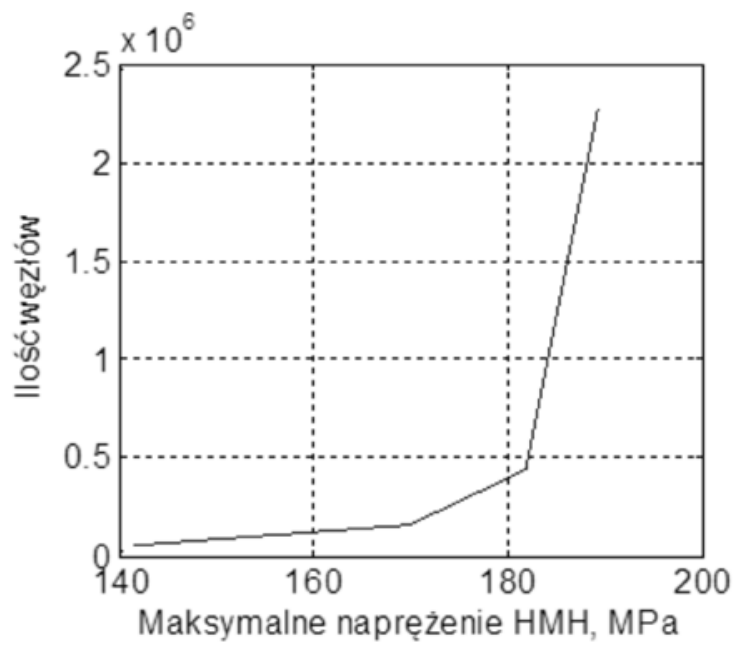

Rys. 4. Wpływ liczby węzłów (MES) na wartość maksymalnego naprężenia $\mathrm{HMH}$

Fig. 4. Influence of a number of nodes on maximal HMH stress

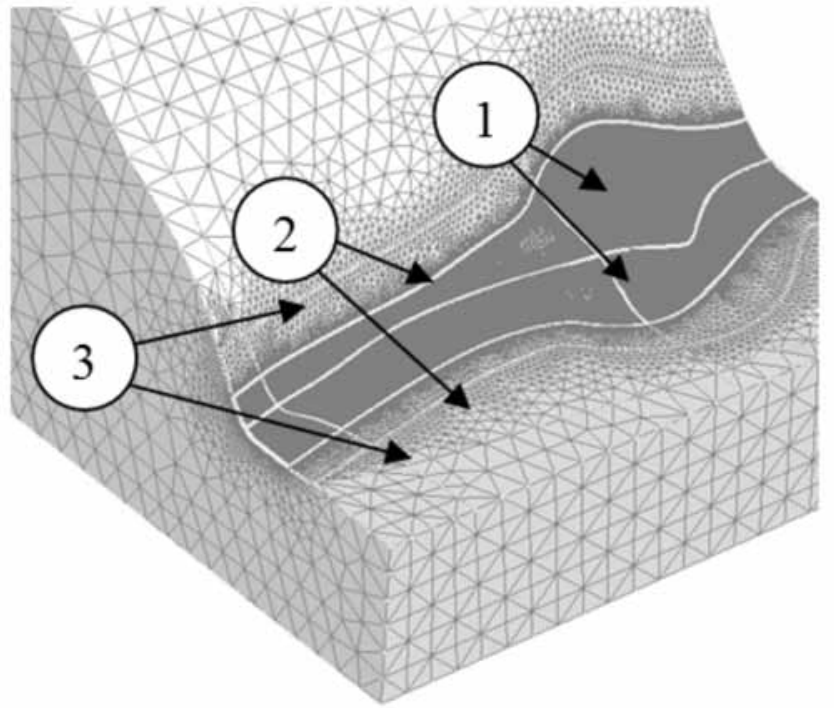

Rys. 5. Oznaczenie obszarów o różnym zagęszczeniu siatki Fig. 5. Marking of areas with different density of a mesh

Tablica I. Wyniki analizy wstępnej

Table I. Results of preliminary analysis

\begin{tabular}{|c|c|c|c|c|c|c|}
\hline \multirow[t]{2}{*}{$\mathrm{Nr}$} & \multicolumn{4}{|c|}{$\begin{array}{c}\text { Wymiar elementów } \\
\text { w obszarach wg rysunku } 5\end{array}$} & \multirow{2}{*}{$\begin{array}{l}\text { Liczba } \\
\text { węzłów }\end{array}$} & \multirow{2}{*}{$\begin{array}{l}\text { Napr. max. } \\
\text { HMH, MPa }\end{array}$} \\
\hline & 1 & 2 & 3 & poz. & & \\
\hline 1 & 0,5 & 0,5 & 0,5 & 0,5 & 58395 & 141,4 \\
\hline 2 & 0,1 & 0,3 & 0,5 & 1 & 158181 & 169,9 \\
\hline 3 & 0,05 & 0,1 & 0,5 & 1 & 442794 & 181,9 \\
\hline 4 & 0,02 & 0,1 & 0,5 & 1 & 2271178 & 189,3 \\
\hline
\end{tabular}

$\mathrm{HMH}$ - według hipotezy Hubera-Misesa-Hencky'ego

Ponieważ analizie poddano $1 / 4$ próbki, pozostała jej część została zasymulowana przez odpowiednie odebranie stopni swobody na płaszczyznach podziału. Dodatkowo odebrano część stopni swobody w miejscu przyłożenia obciążenia, symulując uchwyt. Próbkę obciążono naprężeniem nominalnym $80 \mathrm{MPa}$. Schemat obciążeń i utwierdzeń przedstawiono na rysunku 6.

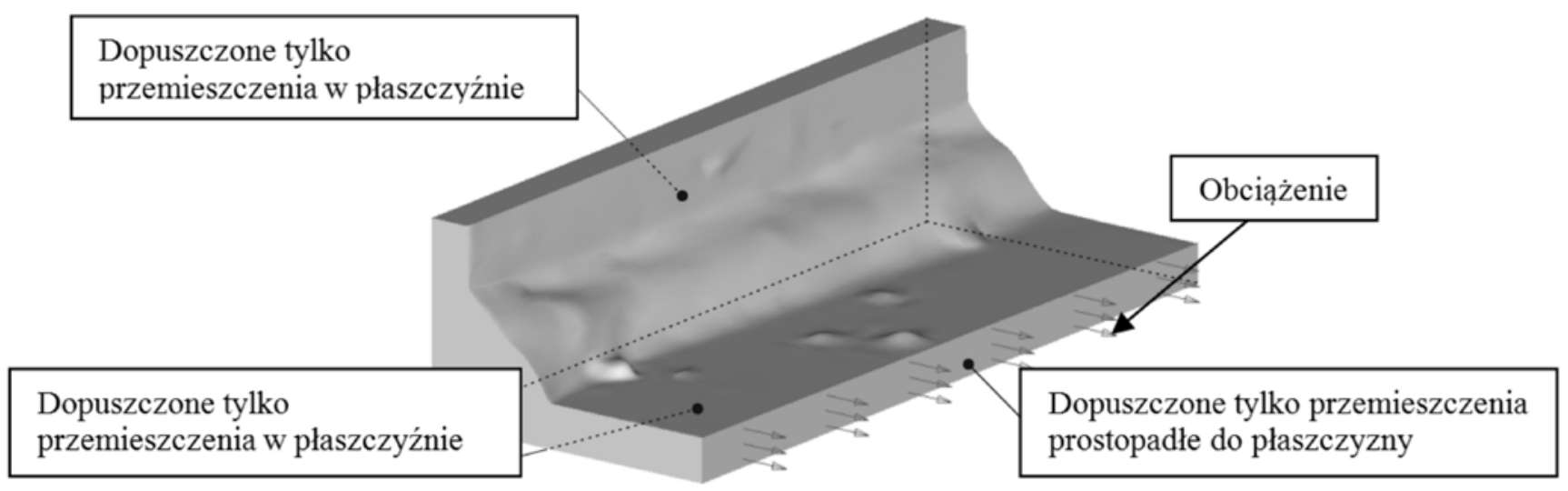

Rys. 6. Schemat obciążeń i utwierdzeń

Fig. 6. Scheme of a loads and constrains 


\section{Wyniki analizy}

Przeprowadzono analizę statyczną z użyciem modelu ciała liniowo-sprężystego. Mapę naprężeń (HMH) przykładowej próbki pokazano na rysunku 7 (dla przypadku 3, tabl. I). Wyniki analizy wszystkich próbek przedstawiono $\mathrm{w}$ tablicy II.

W celu dalszej obróbki danych otrzymanych podczas analizy przeniesiono informacje o modelu i wyniku obliczeń do środowiska Matlab. Posłużono się plikami tekstowymi tworzonymi automatycznie za pomocą Femap, zawierającymi dane o węzłach, elementach oraz naprężeniach. Pliki przeniesiono do Matlaba przy użyciu stworzonego $w$ tym celu skryptu. Operacja ta umożliwiła swobodne przetwarzanie danych, a także połączenie w całość ćwiartek próbki. Na rysunku 8 przedstawiono wykres naprężeń maksymalnych dla próbek 1 i 2 . Linią poziomą zaznaczono wartość naprężeń dla próbki porównawczej.

W celu zobrazowania rozkładu naprężeń występujących w próbce wyznaczono funkcję masy prawdopodobieństwa (probability mass function - pmf) naprężeń dla modeli dyskretnych złącza spawanego. Funkcja ta jest dyskretnym odpowiednikiem gęstości prawdopodobieństwa (probability density function - pdf) [6]. W omawianym przypadku określa prawdopodobieństwo wystąpienia danej wartości naprężenia w badanej próbce. Obliczenia wykonano, wyznaczając objętość poszczególnych elementów skończonych przy znajomości naprężeń $w$ danym elemencie. Pozwoliło to na wyznaczenie wartości funkcji na podstawie zależności (1).

$$
p m f\left(\sigma_{H M H}\right)=\operatorname{Prob}\left\{\left[\sigma=\sigma_{H M H}\right]\right\}=\frac{V\left(\sigma=\sigma_{H M H}\right)}{V_{o}}
$$

gdzie: $V\left(\sigma=\sigma_{\text {нмН }}\right)$ - objętość materiału o danej wartości naprężeń; $V_{0}$ - objętość materiału dla naprężeń $\sigma_{\text {нмН }}>80 \mathrm{MPa}$.

Na rysunku 9 przedstawiono wyniki otrzymane oddzielnie dla każdej ćwiartki, a na rysunku 10 zobrazowano wartości dla całej próbki.

Tablica II. Wyniki obliczeń

Table II. Results of a calculations

\begin{tabular}{|c|c|}
\hline $\begin{array}{c}\text { Nr próbki } \\
-\mathrm{nr} \text { ćwiartki }\end{array}$ & $\begin{array}{c}\text { Maksymalne } \\
\text { naprężenie HMH } \\
\mathrm{MPa}\end{array}$ \\
\hline $1-1$ & 166,4 \\
\hline $1-2$ & 152,1 \\
\hline $1-3$ & 132,9 \\
\hline $1-4$ & 156,1 \\
\hline $2-1$ & 147,8 \\
\hline $2-2$ & 139,2 \\
\hline $2-3$ & 117,6 \\
\hline $2-4$ & 128,6 \\
\hline $\begin{array}{c}\text { Porównawcza } \\
\text { (rys. 3) }\end{array}$ & 144,4 \\
\hline
\end{tabular}

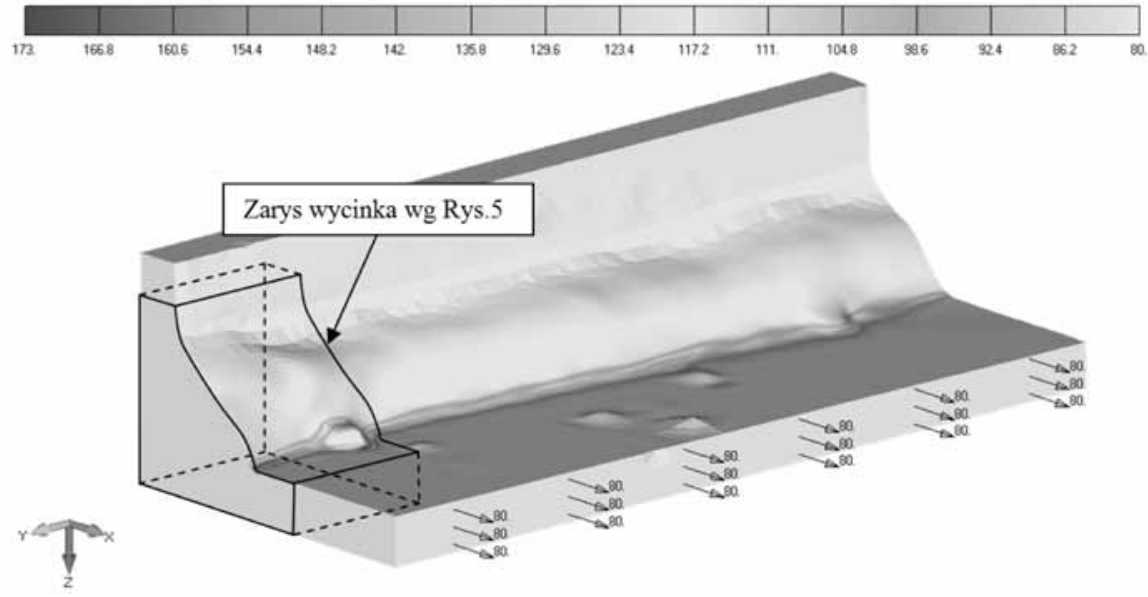

Rys. 7. Naprężenia wg HMH

Fig. 7. The HMH stress distribution
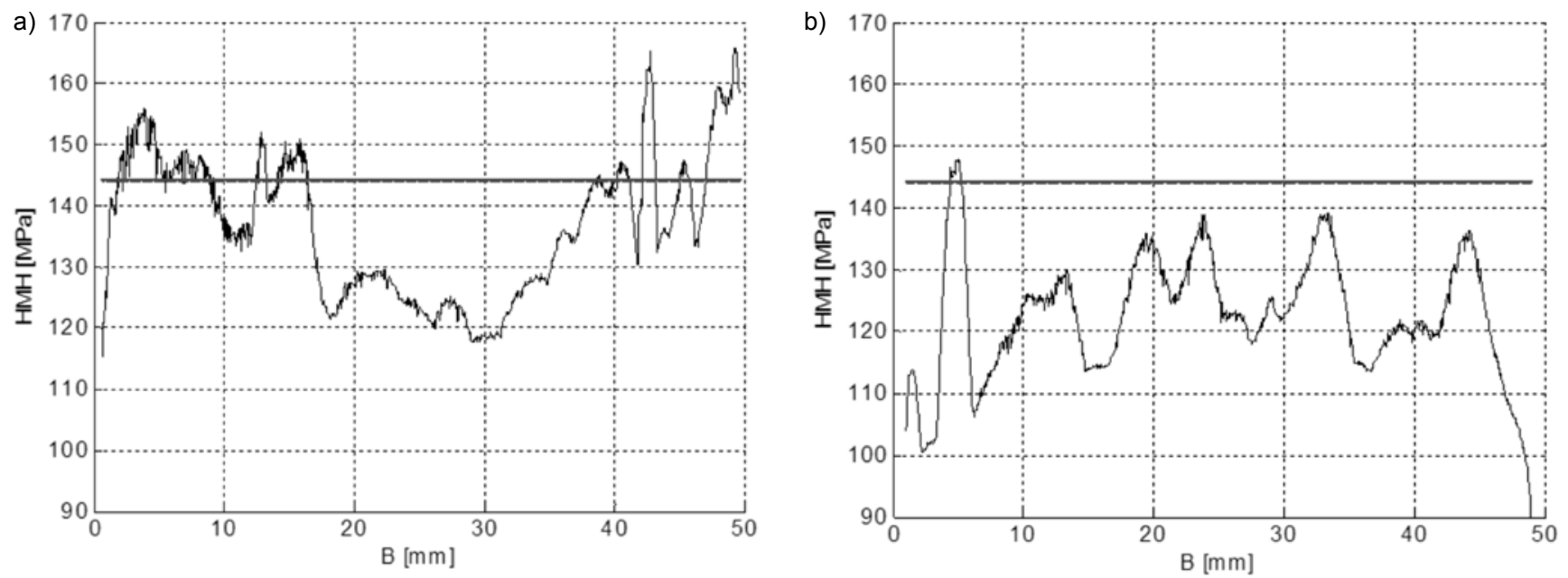

Rys. 8. Naprężenia w próbce wg hipotezy HMH: a) próbka 1, b) próbka 2

Fig. 8. The HMH stress in the specimen: a) specimen 1, b) specimen 2 


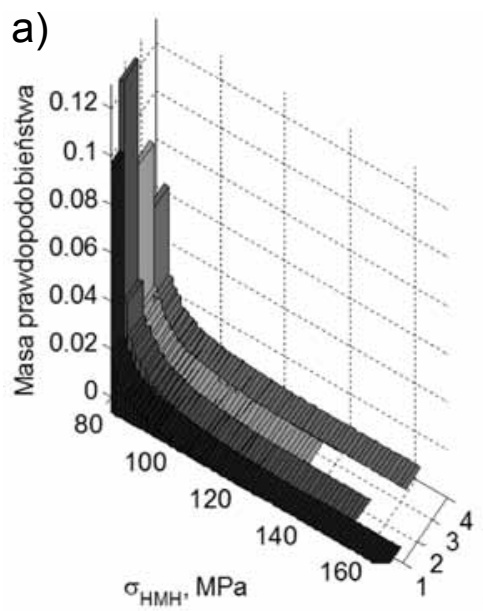

Ćwiartki

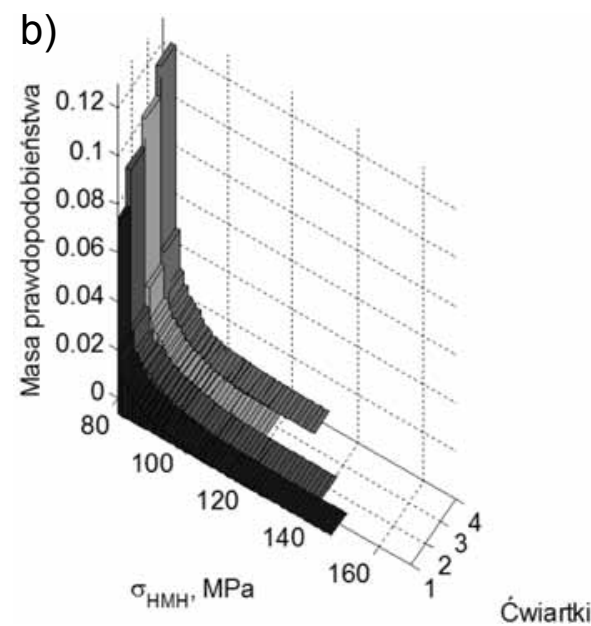

Rys. 9. Funkcja masy prawdopodobieństwa dla ćwiartek próbek: a) 1, b) 2

Fig. 9. Probability mass function for quarter of specimen: a) 1, b) 2
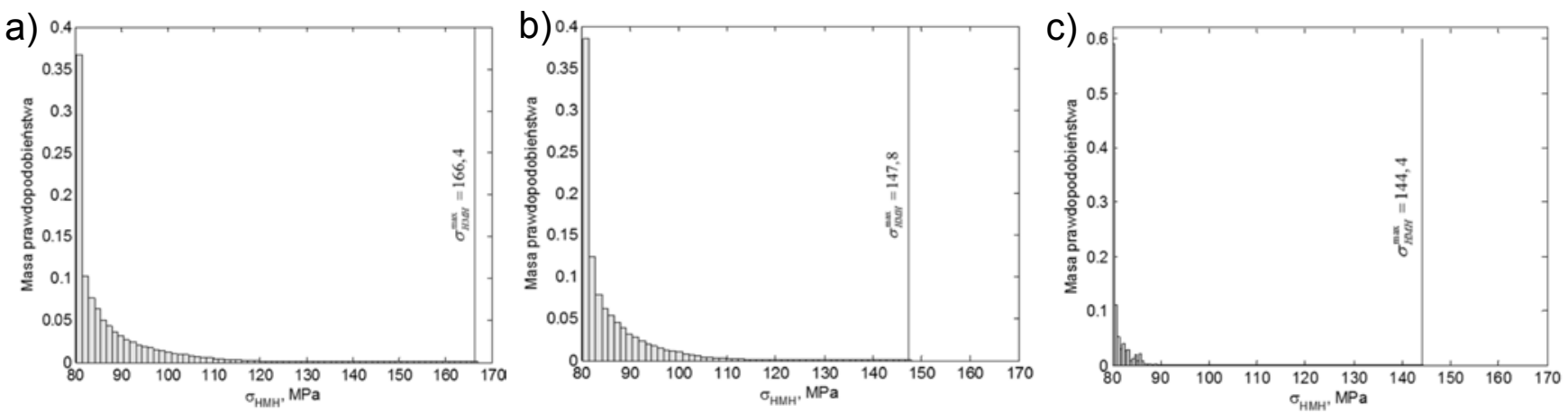

Rys. 10. Funkcja masy prawdopodobieństwa dla próbek: a) 1, b) 2, c) próbki porównawczej

Fig. 10. The probability mass function for specimen: a) 1 , b) 2, c) the comperative specimen

\section{Wnioski}

Przeprowadzona analiza umożliwia wyznaczenie rozkładu naprężeń w złączu przy uwzględnieniu niejednorodności kształtu spoiny. Wykres funkcji masy prawdopodobieństwa daje możliwość oceny nie tylko wartości naprężeń w złączu, ale również pokazuje, jak duża część elementu przenosi podwyższone naprężenia. Pozwala na przedstawienie w przestrzeni dwuwymiarowej przestrzennego stanu naprężeń w całej próbce. Wyznaczenie funkcji masy prawdopodobieństwa dla większej liczby próbek mogłoby wyeliminować konieczność prowadzenia obliczeń MES dla tego typu złącza. Znając funkcję masy prawdopodobieństwa, można dokonać oceny trwałości zmęczeniowej przy wykorzystaniu metody opartej na koncepcji najsłabszego ogniwa zaproponowanej w pracy [7].

Porównując wartości otrzymane dla próbki rzeczywistej z wartościami dla elementu zamodelowanego według wytycznych IIW można stwierdzić, że naprężenia w rzeczywistej konstrukcji są wyższe, a ponadto większa objętość złącza narażona jest na działanie podwyższonego (większego od nominalnego) naprężenia.

\section{Literatura}

[1] Blacha Ł., Karolczuk A., Bański R., Stasiuk P.: Eksperymentalna analiza trwałości zmęczeniowej krzyżowych złączy spawanych w odniesieniu do wielkości elementu. Acta Mechanica et Automatica, vol. 5, s. 16 $\div 20$, Białystok 2011.

[2] Hobbacher A.: Recommendations for fatigue design of weIded joint and components, IIW document IIW-1823-07 ex XIII-2151r4-07/XV-1254r4-07, Paris 2008.

[3] Kaffenberger M., Malikoutsakis M., Savaidis G., Vormwald M.: Fatigue resistance of weld ends. Computational Materials Science, 52(2012), s. $287 \div 292$.

[4] Blacha Ł., Karolczuk A., Łagoda T.: Modeling of stress in weIded joints under consideration of plastic strains in fatigue life

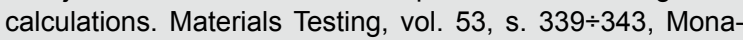
chium 2011.

[5] Hou C-Y...Fatigue analysis of welded joints with the aid of real three-dimensional weld toe geometry. International Journal of Fatigue, 29(2007), s. 772 $\div 785$

[6] Stewart W.J.: Probability, Markov Chains, Queues, and Simulation. The Mathematical Basis of Performance Modeling. Princeton University Press. s. 105. Princeton 2011.

[7] Karolczuk A., Blacha Ł.: Koncepcja najsłabszego ogniwa w modelowaniu trwałości zmęczeniowej złączy spawanych.

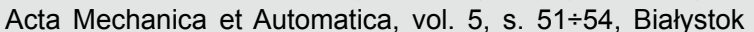
2011. 